\title{
LA URGENCIA DE LA ETNOGRAFÍA JURÍDICA EN AMÉRICA LATINA
}

\author{
THE URGENCY OF LEGAL ETHNOGRAPHY IN LATIN AMERICA
}

\section{Mauricio Chamorro-Rosero ${ }^{1}$}

En el año 2004, la abogada Gina Chávez y el antropólogo Fernando García publicaron con el apoyo financiero de Petroecuador, el auspicio del Consejo de Desarrollo de las Nacionalidades y Pueblos del Ecuador (CODENPE) y la Facultad Latinoamericana de Ciencias Sociales (FLACSO) el libro titulado: El derecho a ser: diversidad, identidad y cambio, Etnografia jurídica indígena y afroecuatoriana. En dicho libro los autores argumentan que "el derecho estatal es en sí mismo plural, porque está afectado por otros órdenes normativos, el derecho internacional, el transnacional y también por las legalidades no estatales (los sistemas de derecho indígena y afro-ecuatoriano en este caso)" (Chávez \& García, 2004, p. 19). De esta forma, a partir de estudios de caso en pueblos kichwa, achuar y shuar de la Amazonia y en el pueblo afroecuatoriano del norte de la provincia de Esmeraldas, los autores recopilan y analizan información sobre sistemas de derecho indígena y afroecuatoriano, e igualmente entregan pistas determinantes sobre la práctica del derecho ancestral.

1. Doctorando en Sociología y Antropología (UCM). Miembro del Grupo de Investigación La Minga. Universidad Cooperativa de Colombia-Pasto, Colombia. Correo: mauricio.254@hotmail.com
El libro se encuentra dividido en tres partes. En la primera de ellas se explora la etnografía jurídica de cada pueblo seleccionado; inicia por el contexto histórico general para -posteriormente ahondar en los principales elementos que componen los sistemas de derecho. Como afirman los autores, "la identificación de sus sistemas normativos y de autoridad se encauzo en un marco de análisis sustancialmente conducido por los propios actores, en una dinámica de reflexión sobre los hechos que iba entre el antes y el ahora", lo que posibilitó demostrar "las particularidades y especificidades de cada pueblo y nacionalidad, así como los diversos grados de importancia que tienen unas y otras actitudes o comportamientos en los distintos grupos" (Chávez \& García, 2004, p. 24). De cierta forma, las etnografías presentan las disputas e impactos del derecho formal (estatal) frente a los sistemas de control interno (de los pueblos indígenas y afro-ecuatorianos) que reconoce la Constitución Política del Ecuador de 1998.

En la segunda parte del libro, titulada Efectos en los sistemas normativos y de control social indigenas y afro-ecuatorianos de los cambios sociales, políticos, económicos y culturales recientes, Chávez y García procuran hacer una reflexión 
sobre los principales hallazgos de los sistemas de derecho indígenas y afroecuatorianos teniendo en cuenta los contextos históricos y sociales de cada pueblo. Esas lógicas sociales demuestran que en el contexto material e histórico "estas comunidades han configurado no solo su identidad étnica y cultural, su organización interna y su relación con el 'otro', sino que también han conformado sistemas normativos y de control social que les rigen y sostienen" (Chávez \& García, 2004, p. 161). Sin embargo, el ejercicio efectivo de las capacidades jurisdiccionales y del Derecho de los pueblos indígenas y afroecuatorianos aún se encuentra pendiente, tornándose en un tema político más que legal.

Para concluir el libro, en su última parte los autores realizan un balance de las relaciones de los sistemas de Derecho indígena y afroecuatoriano con el sistema formal. Para los autores, "contestar a la pregunta de cuándo se aplica el uno o el otro derecho resulta todavía difícil, ya que el derecho indígena y afro no utiliza en forma sistemática el registro de sus acciones y procedimientos, debido al carácter prioritariamente oral de sus prácticas" (Chávez \& García, 2004, p. 201). Por esa razón, el proyecto intercultural podría ser el anclaje para observar un pluralismo jurídico real.

Finalmente, vale rescatar el gran trabajo etnográfico y jurídico realizado por los autores. El análisis del pluralismo jurídico contenido en el derecho formal (en las Constituciones Políticas) se ha convertido en una mera muletilla retorica para varios ordenamientos jurídicos en Latinoamérica, por esa razón, este tipo de estudios son muy pertinente para repensar y debelar las políticas estatales en materia jurídica. Por otra parte, esta investigación ratifica la complementariedad de las ciencias sociales y el importante aporte desde una posición crítica a los mandatos formales del Estado.

\section{REFERENCIA}

Chávez, Gina \& García, Fernando (2004). El derecho a ser: diversidad, identidad y cambio, Etnografia jurídica indígena y afroecuatoria$n a$, FLACSO, sede Ecuador, Quito. 